\title{
Article
}

\section{The positive predictive value of asymmetrical skin creases in the diagnosis of pathological developmental dysplasia of the hip}

Anderton, M.J., Hastie, G.R. and Paton, Robin W.

Available at http://clok.uclan.ac.uk/22602/

Anderton, M.J., Hastie, G.R. and Paton, Robin W. (2018) The positive predictive value of asymmetrical skin creases in the diagnosis of pathological

developmental dysplasia of the hip. The Bone and Joint Journal, 100-B (5). pp. 675-679. ISSN 2049-4394

It is advisable to refer to the publisher's version if you intend to cite from the work. http://dx.doi.org/10.1302/0301-620X.100B5.BJJ-2017-0994.R2

For more information about UCLan's research in this area go to http://www.uclan.ac.uk/researchgroups/ and search for <name of research Group>.

For information about Research generally at UCLan please go to http://www.uclan.ac.uk/research/

All outputs in CLoK are protected by Intellectual Property Rights law, including Copyright law. Copyright, IPR and Moral Rights for the works on this site are retained by the individual authors and/or other copyright owners. Terms and conditions for use of this material are defined in the policies page. 


\begin{tabular}{|c|c|}
\hline Article ID & BJJ-2017-0994.R2 \\
\hline Article Title & $\begin{array}{l}\text { The positive predictive value of asymmetrical skin creases in the diagnosis of pathological } \\
\text { developmental dysplasia of the hip }\end{array}$ \\
\hline Article Type & Hip \\
\hline \multicolumn{2}{|l|}{ JATS Article Type } \\
\hline \multicolumn{2}{|l|}{ Article Subtitle } \\
\hline TOC Term & Hip \\
\hline Subject Group & Hip \\
\hline Keywords & DDH, Developmental dysplasia of the hip, Asymmetrical skin creases \\
\hline \multicolumn{2}{|l|}{ Associated Societies } \\
\hline Author Name [1] & M. J. Anderton \\
\hline Author Degree(s) [1] & MBChB (Hons), MRCS, FRCS(Tr\&Orth) \\
\hline Author Job Title [1] & Spinal Surgery Fellow \\
\hline Author Institution [1] & Royal Adelaide Hospital \\
\hline Author Address [1] & Port Road, Adelaide, Australia \\
\hline \multicolumn{2}{|l|}{ Author ID [1] } \\
\hline Author Contribution [1] & $\begin{array}{l}\text { Conception of the study, Reviewing the literature, Collecting and analyzing the data, Writing, } \\
\text { revising, and approving the manuscript. }\end{array}$ \\
\hline Author Name [2] & G. R. Hastie \\
\hline Author Degree(s) [2] & MBChB, MRCS \\
\hline Author Job Title [2] & Trauma and Orthopaedic Specialist Trainee, Department of Trauma and Orthopaedics \\
\hline Author Institution [2] & Royal Blackburn Teaching Hospital, East Lancashire Hospitals NHS Trust \\
\hline Author Address [2] & Haslingden Road, Blackburn, UK \\
\hline \multicolumn{2}{|l|}{ Author ID [2] } \\
\hline Author Contribution [2] & Collecting the data, Approving the manuscript. \\
\hline Author Name [3] & R. W. Paton \\
\hline Author Degree(s) [3] & FRCS, FRCS (Orth), PhD, FFST \\
\hline Author Job Title [3] & Consultant Orthopaedic Surgeon \\
\hline Author Institution [3] & Royal Blackburn Teaching Hospital, East Lancashire Hospitals NHS Trust \\
\hline Author Address [3] & $\begin{array}{l}\text { Haslingden Road, Blackburn, UK and Visiting Professor, School of Medicine, University of Central } \\
\text { Lancashire, Preston, UK }\end{array}$ \\
\hline \multicolumn{2}{|l|}{ Author ID [3] } \\
\hline Author Contribution [3] & $\begin{array}{l}\text { Designing the study, Collecting and analyzing the data, Reviewing, revising, and approving the } \\
\text { manuscript. }\end{array}$ \\
\hline
\end{tabular}




\begin{tabular}{|c|c|}
\hline Principal Institution & Royal Blackburn Teaching Hospital, East Lancashire Hospitals NHS Trust, Blackburn, United Kingdom \\
\hline Correspondence & Correspondence should be sent to M. J. Anderton; email: mike.anderton@doctors.org.uk \\
\hline Abstract & $\begin{array}{l}\text { Aims } \\
\text { The aim of this study was to identify the association between asymmetrical } \\
\text { skin creases of the thigh, buttock or inguinal region and pathological } \\
\text { developmental dysplasia of the hip (DDH). } \\
\text { Patients and Methods } \\
\text { Between } 1 \text { January } 1996 \text { and } 31 \text { December 2016, all patients referred to } \\
\text { our unit from primary or secondary care with risk factors for DDH were } \\
\text { assessed in a "one stop" clinic. All had clinical and sonographic assessment } \\
\text { by the senior author (RWP) with the results being recorded prospectively. } \\
\text { The inclusion criteria for this study were babies and children referred with } \\
\text { asymmetrical skin creases. Those with a neurological cause of DDH were } \\
\text { excluded. The positive predictive value (PPV) for pathological DDH was } \\
\text { calculated. } \\
\text { Results } \\
\text { A total of } 105 \text { patients met the inclusion criteria. There were } 71 \text { girls and } \\
34 \text { boys. Only two were found to have pathological DDH. Both also had } \\
\text { unilateral limited abduction of the hip in flexion and a positive Galeazzi } \\
\text { sign with apparent leg-length discrepancy. Thus, if the specialist } \\
\text { examination of a patient with asymmetrical skin creases was normal, the } \\
\text { PPV for DDH was } 0 \% \text {. } \\
\text { Conclusion } \\
\text { Isolated asymmetrical skin creases are an unreliable clinical sign in the } \\
\text { diagnosis of pathological DDH. Greater emphasis should be placed on the } \\
\text { presence of additional clinical signs to guide radiological screening in } \\
\text { babies and children. } \\
\text { Key messages: } \\
\text { - This study confirms that asymmetrical skin creases are an unreliable clinical sign in the diagnosis of } \\
\text { pathological developmental dysplasia of the hip. If the hip joint is clinically normal, it is highly un- } \\
\text { likely there will be an association with pathological developmental dysplasia of the hip. Routine } \\
\text { radiological and sonographic imaging of the hip joints is unnecessary if there is no limitation of hip } \\
\text { abduction and normal leg lengths (negative Galleazzi). Newborn and infant physical examination } \\
\text { guidelines should reflect this. } \\
\text { Cite this article: Bone Joint s } 2018 ; 100-B: ? ?-? \text { ? . }\end{array}$ \\
\hline NLM Journal ID & Bone Joint J \\
\hline Print ISSN & $2049-4394$ \\
\hline Article Year & 2018 \\
\hline Online ISSN & 2049-4408 \\
\hline Issue No & 5 \\
\hline Volume No & $100-B$ \\
\hline Page Range & ??-?? \\
\hline
\end{tabular}




\begin{tabular}{|l|l|}
\hline Price & $\$ 2.00$ \\
\hline Copyright Statement & O2018 The British Editorial Society of Bone \& Joint Surgery \\
\hline Funding Statement & $\begin{array}{l}\text { No benefits in any form have been received or will be received from a commercial party related } \\
\text { directly or indirectly to the subject of this article. } \\
\text { This article was primary edited by E. Moulder and first proof edited by J. Scott. }\end{array}$ \\
\hline ICMJE COI Statement & None declared \\
\hline Date Received & \\
\hline Date Accepted & \\
\hline Number of figures & 0 \\
\hline DOI & $10.1302 / 0301-620 X .100$ B5.BJJ-2017-0994.R2 \\
\hline
\end{tabular}


Special instructions/Notes:

We have found the following papers that may be helpful to reference, including two papers written by the senior author. If you would like to cite any of these papers, please indicate where the citation(s) should be inserted. We will then renumber all references in-house.

Nie K, Rymaruk S, Paton RW. Clicky hip alone is not a true risk factor for developmental dysplasia of the hip. Bone Joint J 2017;99-B:1533-1536.

Talbot C, Adam J, Paton R. Late presentation of developmental dysplasia of the hip: a 15-year observational study. Bone Joint J 2017;99-B:1250-1255.

Massa BSF, Guarniero R, Godoy RM Jr, et al. Use of inlet radiographs in the assessment of reduction after the surgical treatment of developmental dysplasia of the hip. Bone Joint J 2017;99-B:697-701.

Please also consider including a reference to Moulder Davies, BJJ proceedings, 2013 this study found the same results as you have:

https://online.boneandjoint.org.uk/doi/abs/10.1302/1358-992x.95bsupp_6.bscos2012016?journalCode=procs 
Developmental dysplasia of the hip joint (DDH) is a dynamic condition, in which minor dysplasia may deteriorate to an irreducible dislocation, or an unstable hip may stabilize within a few weeks.[[1-6]] The abnormality may be physiological or pathological. Pathological DDH is defined on ultrasound as either Graf Type III or IV, or an irreducible dislocation. Risk factors conventionally associated with pathological DDH include female gender, a family history, breech presentation, oligohydramnios, postural and fixed deformities of the foot, caesarean section and torticollis.[[8,9]] However, recent authors have only identified an association with female gender, breech presentation and a family history.[[10-12]] Non-idiopathic instability of the hip can also occur in children with neuromuscular conditions and is not described as DDH.[[7]]

In the United Kingdom, all new born babies undergo clinical assessment for instability of the hip with the Ortolani or Barlow manoeuvres shortly after birth, usually at the place of birth, and six to eight weeks later, usually within primary care. Other clinical signs known to have diagnostic value in pathological DDH are unilateral limitation of abduction of the hip in flexion[[11]] and an apparent limb length discrepancy, which can be seen as a short femur and a positive Galeazzi sign.[[8]] Asymmetrical skin creases can be defined as "asymmetry of the junction of the thigh to the trunk as viewed from the front and of the skin creases on the inside of the thigh".[[8]] They have been reported to be an important clinical sign for DDH since the 1969 Standing Medical Advisory Committee (SMAC) guidelines for hip screening in the United Kingdom. The more recent Newborn and Infant Physical Examination (NIPE) guidelines from Public Health England state that asymmetrical creases are a "screen positive sign" and affected children should be referred for expert assessment to exclude DDH.[[12]] Experts in Europe and the United States have, however, questioned the association between asymmetrical skin creases and DDH in the 
absence of unilateral limitation of abduction of the hip in flexion.[[15-17]] The aim of this study was to investigate this association.

\section{Patients and Methods}

We established a 'one-stop' DDH screening programme in 1992. All babies referred with either risk factors or a clinical suspicion of DDH were assessed by the senior author (RWP) clinically and sonographically. Initially our catchment population included the areas of Blackburn, Darwen, Ribble Valley, and Hyndburn. From 2007 this expanded to include Burnley, Rossendale, and Pendle. Within the clinic, the source and reason for the referral, the age of the child and clinical and sonographic findings were prospectively recorded in a database (Microsoft Excel 2016, Microsoft, Redmond, Washington), which was used to identify the children for this study.

The inclusion criteria were all babies and children referred with asymmetrical skin creases of either the inguinal, adductor or gluteal folds between 1 January 1996 and 31 December 2016. Exclusion criteria included neurological or syndromic aetiology. During the period of the study, there were 113741 births within the catchment area and 7187 referrals to the clinic, of which 105 met the inclusion criteria.

Clinical examination included the Ortolani and Barlow manoeuvres and assessment for unilateral limitation of abduction of the hip in flexion or apparent leg length discrepancy using the Galeazzi sign to examine for a short femur and assessment of leg length.[[8]] A normal examination was defined as a negative Ortolani and Barlow test, a full range of movement of the hips and equal leg lengths. The presence of asymmetrical creases were noted in all cases. Ultrasound imaging was performed with the baby on their side using modified Harcke dynamic and modified Graf static methods and a 5-7.5 MHz linear array transducer (Dornier AL 2200 prior to 2001, Sonosite 180 between 2001 and 2015, and Sonosite M Turbo from 2016).[[9,18]] A pathological hip was defined as a modified Graf 
type III or IV hip, as advocated by Rosendahl et al.[[18,19]] Babies aged under six months with a pathological hip were treated in a Pavlik harness. Those with modified Graf type II hips were classified as physiological and observed with serial sonography and only underwent treatment if the hip progressed to a modified Graf Type III or IV or to an irreducible dislocation. For the purpose of this study, if a Graf Type II hip progressed to a more severe type of dysplasia, the most severe sonographic classification was documented. Those with a Graf Type I hip and a normal examination were discharged.

\section{Statistical analysis}

The results were analysed using sensitivity and positive predictive values (PPV), calculated using $2 \times 2$ contingency tables (Microsoft Excel 2016).

\section{Results}

As shown in Table I, there was a trend towards increased annual referral numbers for babies and children with suspected DDH and asymmetrical skin creases. This was particularly evident after 2008, when there was also a paradoxical decline in live birth rates.

[[TblCap]]Table I. The total live birth rate, total number of referrals to the clinic and number referred with asymmetrical skin creases (ASC) between 1996 and 2016. After 1996, the catchment area included Blackburn, Darwen, Ribble Valley, and Hyndburn; after 2007, it also included Burnley, Rossendale, and Pendle

\begin{tabular}{|l|l|l|l|}
\hline Year & Total live births & Total referrals & ASC referrals \\
\hline 1996 & 3964 & 272 & 1 \\
\hline 1997 & 3767 & 238 & 0 \\
\hline 1998 & 3802 & 273 & 2 \\
\hline 1999 & 3681 & 235 & 4 \\
\hline 2000 & 3692 & 269 & 1 \\
\hline 2001 & 3605 & 353 & 1 \\
\hline 2002 & 3611 & 330 & 2 \\
\hline 2003 & 3785 & 269 & 2 \\
\hline
\end{tabular}




\begin{tabular}{|l|l|l|l|}
\hline 2004 & 3810 & 271 & 2 \\
\hline 2005 & 3882 & 274 & 2 \\
\hline 2006 & 3992 & 323 & 0 \\
\hline 2007 & 7292 & 325 & 2 \\
\hline 2008 & 7554 & 329 & 3 \\
\hline 2009 & 7483 & 320 & 4 \\
\hline 2010 & 7366 & 372 & 8 \\
\hline 2011 & 7280 & 450 & 9 \\
\hline 2012 & 7263 & 424 & 3 \\
\hline 2013 & 7122 & 461 & 7 \\
\hline 2014 & 7017 & 427 & 13 \\
\hline 2015 & 6839 & 445 & 21 \\
\hline 2016 & 6934 & 527 & 18 \\
\hline Total & 113741 & 7187 & 105 \\
\hline
\end{tabular}

There were 71 girls (68\%) and 34 boys (32\%), of whom 94 (90\%) were referred from primary care or community practitioners, the remainder from the new born checks. The age at the time of clinical assessment was bimodal in distribution, with peaks at three months and nine months. Apart from female gender, other recognized risk factors for DDH included one baby with a sibling affected by DDH and four with a breech presentation. None of these were diagnosed with DDH.

The clinical and sonographic findings are shown in Tables II and III. Clinical examination was normal in 84 babies (80\%), all of whom had Graf Type I hips on sonographic imaging. A further $19(18 \%)$ were found to have another significant clinical finding but had normal sonographic imaging (Graf Type I). Only two (2\%) had pathological $\mathrm{DDH}$, with unilateral dislocation of the hip being diagnosed on sonography. Both were referred from primary care: one boy, aged three months and one girl aged ten months. Both had unilateral limitation of abduction of the hip in flexion and an apparent leg-length discrepancy with a positive Galeazzi sign. The referral letter for the girl did not record 
additional abnormal findings, however, the boy was also referred with an apparent leg length discrepancy of $>1 \mathrm{~cm}$ (Galeazzi positive) and decreased abduction in flexion. Both had otherwise normal development and no risk factors for $\mathrm{DDH}$, and both were treated successfully with EUA, arthrogram, closed reduction and a hip spica.

[[TblCap]]Table II. Clinical findings for developmental dysplasia of the hip (DDH) and associated positive predictive value (PPV)

\section{Clinical finding}

$84(80 \%)$ had isolated asymmetrical skin creases (ASC) (of which 0 had DDH, PPV 0\%)

$19(18 \%)$ had ASC plus one other finding (of which 0 had DDH, PPV 0\%)

8 had ASC and limited hip abduction in flexion

11 had ASC and leg length discrepancy

$2(2 \%)$ had ASC plus 2 other factors, both of which were confirmed to have DDH (PPV 100\%)

2 had ASC, limited abduction in flexion and a leg length discrepancy

[[TblCap]]Table III. Results of sonographic assessment; the alpha angle was unavailable for one baby in the series of 105

\begin{tabular}{|c|c|c|}
\hline Alpha angle & Baby's left hip, n & Baby's right hip, n \\
\hline Graf I $\left(>60^{\circ}\right)$ & 101 & 100 \\
\hline Graf IIa \& IIb $\left(50^{\circ}\right.$ to $\left.60^{\circ}\right)$ & $\begin{array}{l}2 \text { - } 1 \text { had a normal clinical } \\
\text { examination, discharged. baby had } \\
\text { reduced abduction on initial } \\
\text { examination. Reviewed at } 6 \mathrm{mths} \text {, } \\
\text { when the asymmetrical crease } \\
\text { remained, but clinical examination } \\
\text { was normal, thus discharged }\end{array}$ & $\begin{array}{l}4 \text { - } 3 \text { had an alpha angle of } 60^{\circ} \text {; } \\
\text { discharged after normal clinical } \\
\text { examination. } 1 \text { had an alpha angle } \\
\text { of } 53^{\circ} \text { and underwent examination } \\
\text { under anaesthetic, arthrography, } \\
\text { closed reduction and a hip spica }\end{array}$ \\
\hline Graf IIc $\left(43^{\circ}\right.$ to $\left.49^{\circ}\right)$ & 0 & 0 \\
\hline Graf III \& IV $\left(<43^{\circ}\right)$ & $\begin{array}{l}\mathbf{1} \text { had an alpha angle of } 40^{\circ} \text {; had } \\
\text { an examination under anaesthetic, } \\
\text { arthrogram, closed reduction and a } \\
\text { hip spica }\end{array}$ & 0 \\
\hline
\end{tabular}


Thus, in babies with isolated asymmetrical skin creases, or asymmetrical creases with only one other clinical finding, as assessed by an experienced specialist, statistical analysis found a sensitivity for dislocation of the hip and a PPV both of $0 \%$. Also, in those with asymmetrical creases and both limited abduction in flexion and an apparent leg-length discrepancy, the sensitivity and PPV were both 100\% (Microsoft Excel 2016).

\section{Discussion}

The true prevalence of asymmetrical skin creases is unknown, although published figures suggest they are present in $20 \%$ to $25 \%$ of babies with normal hip joints.[[20-22]] If all babies found to have asymmetrical creases are referred for assessment, as the current NIPE guidelines suggest,[[12]] the minimum expected number of referrals to our service during the 20 -year period would have been 22748 . As we only received 105, it is probable that many babies were examined by experienced paediatricians and primary care professionals and considered to have a normal hip. However, it highlights an alarming variation in practice. Furthermore, of the 105 referrals, 94 (90\%) were from primary care or the community, which suggests that asymmetrical creases are either dismissed or are not apparent in the neonatal population.

When the rate of late diagnosed DDH was not reduced following the introduction of the Standing Medical Advisory Committee National screening programme[[13]] in 1969, one theory was that the examiners were poorly trained and inexperienced.[[26]] Thus in 2008, the United Kingdom National Screening Committee launched The National Health Service Newborn and Infant Physical Examination programme (NIPE),[[27]] which aimed to ensure that all healthcare professionals conducting examinations were fully trained and competent. It has been repeatedly shown that small groups of dedicated, well-trained examiners have an improved rate of detection of $\mathrm{DDH}$, a reduction in false positive diagnosis and treatment, and a decrease in the rate of late diagnosis.[[23-25]] We acknowledge that there is justification 
for a referral if the primary healthcare professional is not confident enough to exclude DDH. However, individuals tasked to assess hips for DDH clinically should have the appropriate training to identify those hips with known risk factors, such as unilateral limitation of abduction of the hip in flexion or a positive Galeazzi sign.

The NIPE 2008 guidelines paid specific attention to examination of the hips and stated the following: "Check symmetry of the limbs and skin folds. Perform Barlow and Ortolani manoeuvres". Guidelines in the United Kingdom, including the most recent guidance from Public Health England for 2016 to 2017, continue to state the importance of assessing the symmetry of skin creases.[[8,12,27]]

Our study found that following the introduction of the 2008 NIPE guidelines, referrals for asymmetrical skin creases increased, despite a decline in live births within the catchment population (Table I). While it is imperative to maintain a high level of clinical suspicion for DDH, the evidence linking asymmetrical skin creases and DDH, in the absence of associated clinical findings and risk factors, remains weak. Palmen et al[[15]] studied 500 newborns and noted that $27 \%$ had no skin creases, $40 \%$ had symmetrical creases, and $33 \%$ had asymmetrical creases. Four had an abnormal provocative test of hip stability, of which two had symmetrical creases. Barlow,[[28]] in his study of 1962, examined over 9000 infants and found asymmetrical creases in $<50 \%$ of those diagnosed with DDH, and the great majority of those with asymmetrical creases had normal hips.

Omeroğlu and Koparal[[22]] reviewed 188 babies with suspected DDH, and found that the rate of DDH was $38 \%$ in those with asymetrical creases, compared with $10 \%$ in those without $(\mathrm{p}<0.05)$. In this series five children with asymmetrical creases and abnormal ultrasounds had no other positive clinical finding. However, there was no mention of associated risk factors. Hassan and Shannak[[29]] reviewed 370 babies with confirmed DDH, of whom $83 \%$ had asymmetrical creases and at least one other significant clinical finding. 
Stein-Zamir et al[[30]] reviewed 51 babies, several of whom had more than one positive clinical finding, with a PPV of 50\% for asymmetrical creases. While these papers all conclude that asymmetrical creases are an important clinical finding associated with $\mathrm{DDH},[[22,29,30]]$ they present insufficient data to conclude that asymmetrical creases are of clinical significance in the absence of associated clinical findings and risk factors.

The authors of two major systematic review articles found that it is difficult to conclude that asymmetrical skin creases are a useful clinical finding, there being scarce and unsupportive evidence linking asymmetrical creases with pathological DDH.[[17,31]] Our study is unique in its long period of observation and prospective data collection from one experienced clinician (RWP), making it more objective than previous studies. The undisputed clinical signs associated with pathological DDH are unilateral limitation of abduction in flexion after the age of two months, and a positive Galeazzi sign. If these signs were positive, the PPV was $100 \%$. If a baby with asymmetrical creases has either of these clinical signs, radiological or sonographic assessment of the hip joint is imperative. In a baby with asymmetrical creases, normal movement of the hip and equal leg lengths, we found the PPV of DDH is $0 \%$. This would suggest that Public Health England should review their guidelines, as the present recommended 'screen positive' guidance is not evidence-based. Further research in the form of a meta-analysis is warranted.

In conclusion, this study confirms that asymmetrical skin creases are an unreliable clinical sign in the diagnosis of pathological DDH and that most of these babies have a normal hip. If the hip is clinically normal, it is highly unlikely that there will be associated pathological DDH. Routine radiological and sonographic imaging of the hips appears unnecessary if there is no limitation of abduction in flexion and normal leg lengths (negative Galeazzi sign). National guidelines should reflect this. 


\section{References}

1. Klisic PJ. Congenital dislocation of the hip--a misleading term: brief report. J Bone Joint Surg [Br] 1989;71-B:136.

2. Barlow TG. Congenital dislocation of the hip in the newborn. Proc R Soc Med 1966;59(11 Part 1):1103-1106.

3. Gardiner HM, Clarke NM, Dunn PM. A sonographic study of the morphology of the preterm neonatal hip. J Pediatr Orthop 1990;10:633-637.

4. Wood MK, Conboy V, Benson MK. Does early treatment by abduction splintage improve the development of dysplastic but stable neonatal hips? J Pediatr Orthop 2000;20:302-305.

5. Castelein RM, Sauter AJ, de Vlieger M, van Linge B. Natural history of ultrasound hip abnormalities in clinically normal newborns. J Pediatr Orthop 1992;12:423-427.

6. Mace J, Paton RW. Neonatal clinical screening of the hip in the diagnosis of developmental dysplasia of the hip: a 15-year prospective longitudinal observational study. Bone Joint J 2015;97-B:265-269.

7. Bialik V, Bialik GM, Blazer S, et al. Developmental dysplasia of the hip: a new approach to incidence. Pediatrics 1999;103:93-99.

8. Standing Medical Advisory Committee. Screening for the detection of congenital dislocation of the hip. Arch Dis Child 1986;61:921-926.

9. Paton RW, Hinduja K, Thomas CD. The significance of at-risk factors in ultrasound surveillance of developmental dysplasia of the hip. A ten-year prospective study. $J$ Bone Joint Surg [Br] 2005;87-B:1264-1266.

10. Talbot CL, Paton RW. Screening of selected risk factors in developmental dysplasia of the hip: an observational study. Arch Dis Child 2013;98:692-696.

11. Choudry Q, Goyal R, Paton RW. Is limitation of hip abduction a useful clinical sign in the diagnosis of developmental dysplasia of the hip? Arch Dis Child 2013;98:862-866. 
12. No authors listed. Newborn and Infant Physical Examination (NIPE) Screening: Programme Handbook. NHS. Public Health England, 2016.

https://www.gov.uk/government/uploads/system/uploads/attachment_data/file/572685/NIPE_ programme_handbook_2016_to_2017_November_2016.pdf (date last accessed 7 February 2018).[[bibmisc]]

\section{Department of Health and Social Security, Central Health Services Council,} Standing Medical Advisory Committee. Screening for the detection of congenital dislocation of the hip in infants. London: Department of Health and Social Security, 1969.[[bibmisc]]

14. Hall D, Elliman D. Health for All Children. Revised fourth ed. New York: Oxford University Press, 2006.[[bibmisc]]

15. Palmen K. Preluxation of the hip joint. Diagnosis and treatment in the newborn and the diagnosis of congenital dislocation of the hip joint in Sweden during the years 1948-1960. Acta Paediatr Suppl 1961;50(Suppl 129):1-71.

16. Lehmann HP, Hinton R, Morello P, Santoli J. Developmental dysplasia of the hip practice guideline: technical report. Committee on Quality Improvement, and Subcommittee on Developmental Dysplasia of the Hip. Pediatrics 2000;105:E57.

17. Shipman SA, Helfand M, Moyer VA, Yawn BP. Screening for developmental dysplasia of the hip: a systematic literature review for the US Preventive Services Task Force. Pediatrics 2006;117:e557-e576.

18. Rosendahl K, Toma P. Ultrasound in the diagnosis of developmental dysplasia of the hip in newborns. The European approach. A review of methods, accuracy and clinical validity. Eur Radiol 2007;17:1960-1967. 
19. Rosendahl K, Markestad T, Lie RT. Ultrasound screening for developmental dysplasia of the hip in the neonate: the effect on treatment rate and prevalence of late cases. Pediatrics 1994;94:47-52.

20. Sewell MD, Eastwood DM. Screening and treatment in developmental dysplasia of the hip-where do we go from here? Int Orthop 2011;35:1359-1367.

21. Ryder CTMW. The infant's hip—normal or dysplastic? Clin Orthop Relat Res $1962 ; 22: 7-19$.

22. Omeroğlu H, Koparal S. The role of clinical examination and risk factors in the diagnosis of developmental dysplasia of the hip: a prospective study in 188 referred young infants. Arch Orthop Trauma Surg 2001;121:7-11.

23. Macnicol MF. Results of a 25-year screening programme for neonatal hip instability. $J$ Bone Joint Surg [Br] 1990;72-B:1057-1060.

24. Düppe H, Danielsson LG. Screening of neonatal instability and of developmental dislocation of the hip. A survey of 132,601 living newborn infants between 1956 and 1999. $J$ Bone Joint Surg [Br] 2002;84-B:878-885.

25. Krikler SJ, Dwyer NS. Comparison of results of two approaches to hip screening in infants. J Bone Joint Surg [Br] 1992;74-B:701-703.

26. Sewell MD, Rosendahl K, Eastwood DM. Developmental dysplasia of the hip. BMJ 2009;339:b4454.

27. No authors listed. Newborn and Infant Physical Examination Screening: Standards. Public Health England, 2008. https://www.gov.uk (date last accessed 14 March 2018).[[bibmisc]]

28. Barlow T. Early diagnosis and treatment of congenital dislocation of the hip. $J$ Bone Joint Surg [Br] 1962;44-B:292-301. 
29. Abu Hassan FO, Shannak A. Associated risk factors in children who had late presentation of developmental dysplasia of the hip. J Child Orthop 2007;1:205-210.

30. Stein-Zamir C, Volovik I, Rishpon S, Sabi R. Developmental dysplasia of the hip: risk markers, clinical screening and outcome. Pediatr Int 2008;50:341-345.

31. Moen K. Developmental dysplasia of the hip. BMJ Best Practice. Last updated November 2017. http://bestpractice.bmj.com/best-practice/monograph/742.html (date last accessed 7 February 2018).[[bibmisc]] 